\title{
Ultrasound Role in Management of Female Infertility
}

\author{
MAYSA S. ELKERDAWY, M.Sc.; MOHAMMED A. ALI, M.D. and NERMEEN N. KERIAKOS, M.D. \\ The Department of Radio-Diagnosis, Faculty of Medicine, Ain Shams University
}

\begin{abstract}
Background: Investigation of the probable causes of female infertility is complex and in many instances a complicated process.

Aim of Study: To discuss the role of ultrasound in detection of causes of female infertility (including those disorders of cervix, ovaries, fallopian tube and uterus) illustrated by few cases.

Patients and Methods: This cross sectional study was conducted on thirty female patients seeking fertility at Itay scan private radiology center, Itay Elbaroud and Al Dlangat General Hospitals, during the period from January 2018 to January 2020. All patients were subjected to examination using (GE healthcare Voluson P8 and Toshiba Nemio 30 and Medison Sono Ace R3) Ultrasound Machines.

Results: Uterine abnormalities represent about $60 \%$, cervical abnormalities represent $3.3 \%$ and ovarian abnormalities represent $23.3 \%$, while tubal abnormalities represent $13.3 \%$ of the study group. Mean age of uterine abnormalities is about 30.5 years old, cervical abnormalities about 26 years old, ovarian abnormalities about 26 years old while mean age of tubal abnormalities is 30.5 years old in the study group. In most cases of female infertility in our study, ultrasound has been of great value: e.g. uterine malformations (sub septate and bicornuate uterus), endometrial abnormalities (endometrial polyp and focal endometrial hyperplasia), myometrial diseases (fibroids and uterine adenomyosis), tubal abnormalities (including hydrosalpinx and endometriosis), ovarian functional abnormalities (polycystic ovary) and cervical abnormalities (cervical masses).

Conclusion: Ultrasound is a reliable tool in the diagnosis of many anatomical causes of female infertility and is comparable to gold standard investigations in many circumstances, so we recommend it as primary investigation modality that could be complemented by other tools e.g. MRI, HSG, and laparoscopy when needed.
\end{abstract}

Key Words: Female infertility - Ultrasound - Saline infusion sono hysterography.

Correspondence to: Dr. Maysa S. Elkerdawy, The Department of Radio-Diagnosis, Faculty of Medicine, Ain Shams University

\section{Introduction}

EXPERIENCING infertility has a very bad physical and psychological effect on the infertile individual, as well as his/her partner.

Infertility is a disease characterized by the failure to get pregnant after 12 months of regular and unprotected sexual intercourse. It is estimated to affect between 8 and $12 \%$ of reproductive-aged couples worldwide [1].

Female infertility causes can be difficult to diagnose. There are many available treatments, which will depend on the cause of infertility [2]

Evaluation of infertility is multimodal in nature, and imaging plays an integral role in assessing anatomic abnormalities, tubal occlusion, and even ovarian reserve. This review focuses on ultrasound imaging of the uterus, ovaries, fallopian tubes, and pelvic cavity with regard to the assessment of Müllerian duct anomalies, tubal structural abnormalities, intrauterine adhesions, uterine fibroids and endometriosis [3].

Ovarian abnormalities include: Ovarian dysgenesis, premature ovarian failure, androgenic disorders \& polycystic ovarian syndrome. Uterine abnormalities include leiomyomas, mullerian duct anomalies, endometrial polyps, intrauterine adhesions \& adenomyosis. Cervical abnormalities include cervical factor of infertility and cervical stenosis. Tubal abnormalities include tubal occlusion, PID \& endometriosis [4].

Ultrasound is preferred as the initial imaging modality for assessing possible causes of female infertility because of its low cost and convenience, providing a basic assessment of ovarian morphology, uterine structure, and detection of such pathology as uterine fibroids and Müllerian anomalies [2]. 
Ultrasound can also be coupled with color Doppler and 3D/4D scans. It is non-invasive, radiation-free; relatively less time consuming and easily repeatable, moreover, it can be used as part of interventional techniques in treatment of some cases of female infertility. However, there are some short comings with this modality, such as subjective errors, limited field of view, interference by obesity or by gaseous bowel loops, suboptimal visualization of fallopian tubes and broad ligament and failure to delineate small ovaries [5].

\section{Aim of the study:}

The purpose of this review is to discuss the role of ultrasound in detection of causes of female infertility including those disorders of cervical, ovarian, fallopian tube and uterine origin illustrated by few cases. We will also mention shortly some intervention techniques in which ultrasound guidance could be of value.

\section{Patients and Methods}

This cross sectional study was conducted on thirty female patients seeking fertility referred to ultrasound unit from obstetric and gynacology clinic searching for causes of infertility either primary or secondary, 13 patients had primary infertility and 17 others had secondary infertility. The mean age of the study group was 31.5 years old. Their main complaint was menorrhagia and the least complaint was recurrent offensive vaginal discharge. The study took place at Itay scan private radiology center (17 cases), Itay Elbaroud and $\mathrm{Al}$ Dlangat General Hospitals (8 and 5 cases respectively) over a period of two years starting from January 2018 to Jan 2020. All patients were examined using (GE healthcare Voluson P8 and Toshiba Nemio 30 and Medison Sono Ace R3) Ultrasound Machines. The study was limited to only females who were willing and give consent to undergo additional investigations.

Inclusion criteria: Age ranged from 18 to 45 years old, complaining of either primary or secondary infertility with regular unprotected intercourse and without using any method of contraception.

Exclusion criteria: Patients not having regular intercourse (less than 2-3 times a week including peri-ovulatory days) or patients having other known causes of infertility not related to female reproductive system (e.g. hormonal disturbance; including pituitary, adrenal and thyroid glands).

All patients were subjected to the following: History taking, clinical examination and radiolog- ical evaluation (including: Gray scale $+/$ - color Doppler ultrasound using either trans abdominal, trans vaginal ultrasound machines or both). Reassurance and explanation of the steps of the study in details to patients Some patients were referred to perform saline infusion sonography (to confirm endometrial pathology, such as polyps, hyperplasia, cancer, leiomyomas, and adhesions) or three D ultrasound. Complete standard sonographic evaluation of the pelvic cavity was performed to characterize the etiology of reproductive organs abnormalities causing infertility. The patients were instructed to have full bladder when subjected to abdominal ultrasound examination and to empty the bladder before transvaginal examination. Oral consents were taken from all cases Results were confirmed using complementary diagnostic imaging modalities e.g. HSG, histopathological examination, hormonal assessment or MRI pelvic study (as a gold standard tools for corresponding pathologies).

\section{Ultrasound technique:}

Using both low and high frequency transducers (abdominal and transvaginal probes) for examination of female pelvis searching for anatomical and functional causes of female factor of infertility.

Saline infusion sono-hysterography refers to a procedure in which fluid is instilled into the uterine cavity trans cervically to provide enhanced endometrial visualization during transvaginal ultrasound examination. SIS is performed using A $6 \mathrm{~F}$ $8 \mathrm{~F}$ balloon catheter or a canula specially devised for SIS or HSG is attached to a $10 \mathrm{ml}$ syringe prefilled with saline. The catheter is introduced through cervix into the uterus. No potential risks are expected, as ultrasound is a radiation free imaging tool.

Patients' positioning: supine with knees extended in abdominal examination and lithotomy position in case of trans-vaginal examination and saline infusion sonography.

Evaluation criteria: Evaluation of the female pelvis includes using optimal imaging planes (longitudinal and transverse). Some patients were complementary examined using sono hysterography technique or three D ultrasound.

Diagnosis: Sub septate uterus confirmed by MRI (D image).

Diagnosis: Endometrioma of left ovary with retracted thrombus, confirmed after surgical removal and histological examination.

Diagnosis was confirmed by histopathology to be endometrial polyp. 

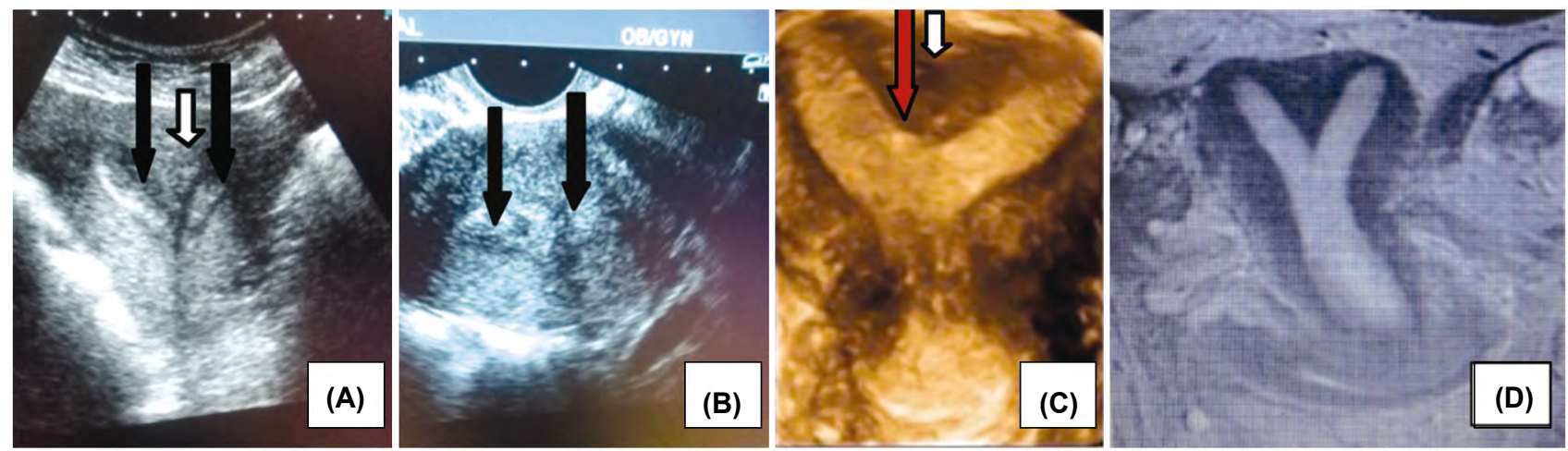

Fig. (1): 30 years old female patient came for assessment of primary infertility. Patient had recurrent miscarriage. (A\&B images) TA US images longitudinal and TS section respectively through uterine fundus showing two divergent endometrial stripes (black arrows) the external cleft $<1 \mathrm{~cm}$ (white arrow), while internal indentation on endometrium $>1.5 \mathrm{~cm}$ (red arrow). C image: Showing 3D reconstructed image of the same case.
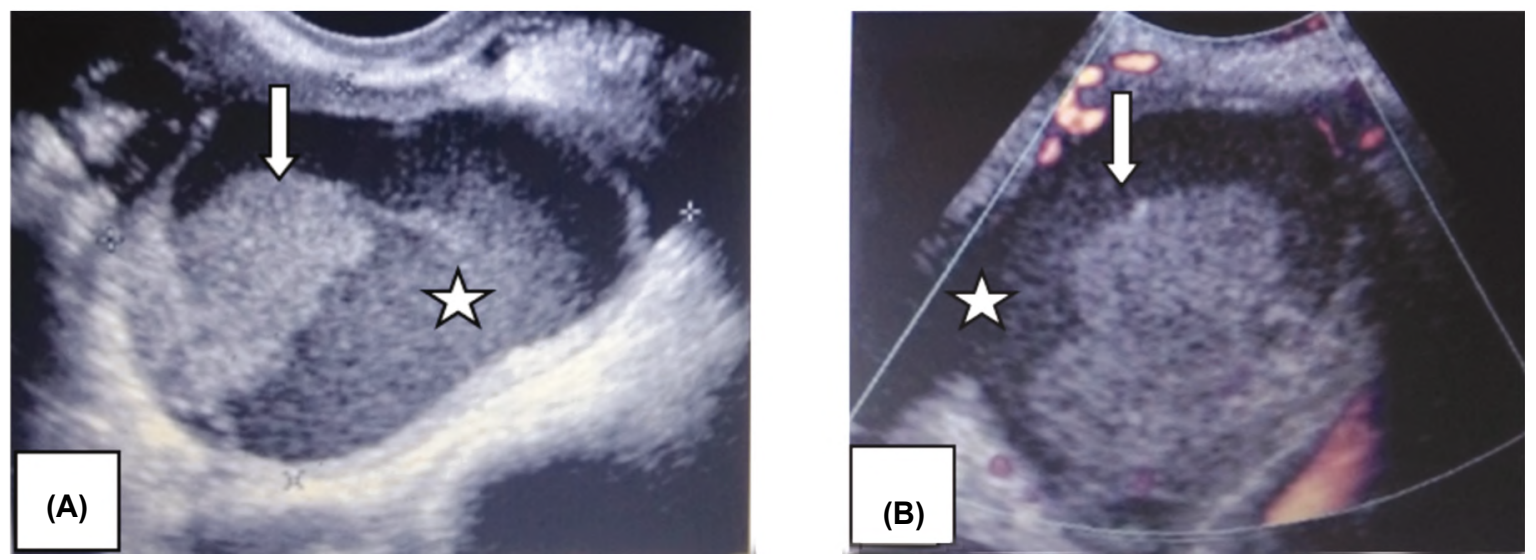

Fig. (2): 38 years old female patient has irregular menstrual cycles and associated left side pelvic pain not related to menses. Patient had secondary infertility. (image A) grey scale trans-vaginal ultrasound image of left adnexa revealed large rounded complex cyst with slightly irregular thick wall and showing homogenous low level internal echoes (white star) with inside echogenic nodule adherent to the wall (white arrow), color Duplex detected minimal vascularity in the wall with no intenral vascularity of the nodule (image B).
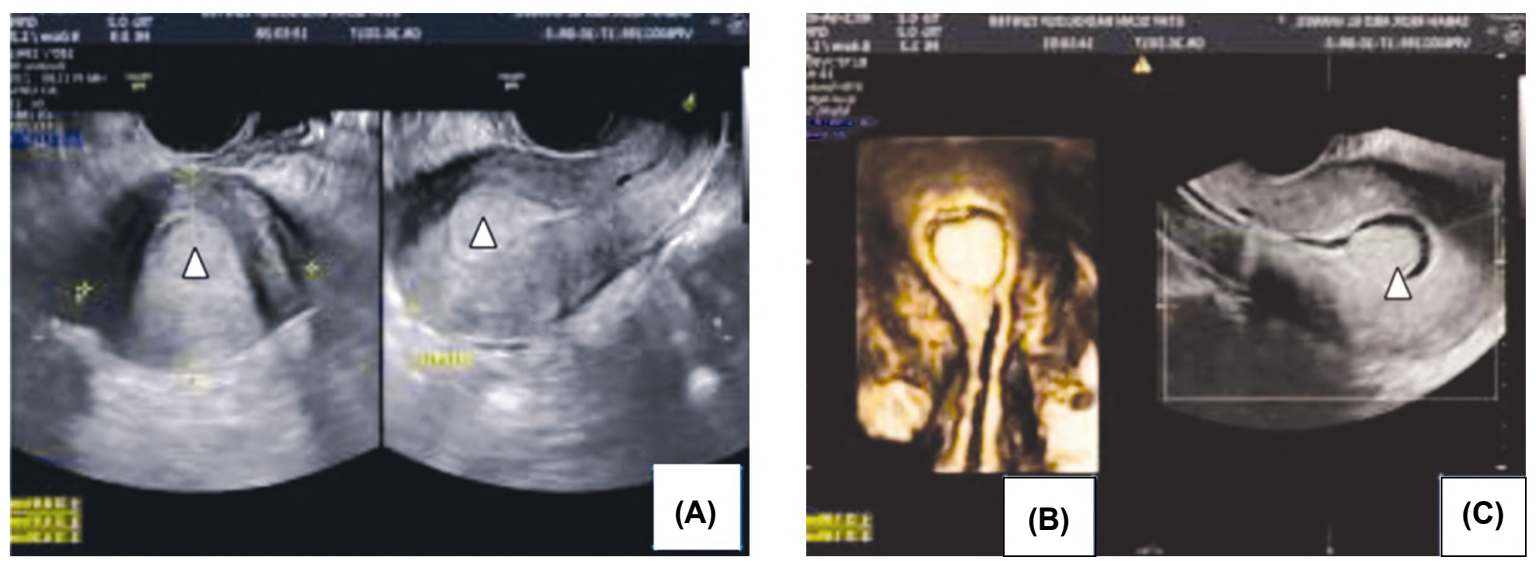

Fig. (3): 33 years old female patient complaining of previous miscarriage came for assessment of primary infertility (image A): Grey scale TV US images both transverse and longitudinal sections respectively showing hyperechoic endometrial lesions (white arrow head). (Image B): Confirmed the presence of anterior wall endometrial polyp by both saline infusion sono hysterography (image $\mathrm{C}$ ) and $3 \mathrm{D}$ coronal reconstruction (image $\mathrm{B}$ ). 


\section{Results}

Table (1): Age distribution of the study group.

\begin{tabular}{lll}
\hline Age in years & No. & $\%$ \\
\hline 18-25 years old & 11 & 36.6 \\
26-35 years old & 12 & 40 \\
$36-45$ years old & 7 & 23.3 \\
\hline
\end{tabular}

Table (2): Percentage of different causes of infertility detected by ultrasound in the study group.

\begin{tabular}{lccccc}
\hline $\begin{array}{l}\text { Ultrasound } \\
\text { finding }\end{array}$ & $\begin{array}{c}\text { Uterine } \\
\text { abnor- } \\
\text { malities }\end{array}$ & $\begin{array}{c}\text { Cervical } \\
\text { abnor- } \\
\text { malities }\end{array}$ & $\begin{array}{c}\text { Ovarian } \\
\text { abnor- } \\
\text { malities }\end{array}$ & $\begin{array}{c}\text { Tubal } \\
\text { abnor- } \\
\text { malities }\end{array}$ & Total \\
\hline $\begin{array}{l}\text { No. } \\
\%\end{array}$ & 18 & 1 & 7 & 4 & 30 \\
\hline
\end{tabular}

Table (3): Percentage of different ovarian pathologies detected by ultrasound in the study group.

\begin{tabular}{llcl}
\hline Ovary & PCO & $\begin{array}{c}\text { Premature } \\
\text { ovarian failure }\end{array}$ & Total \\
\hline $\begin{array}{l}\text { No. } \\
\%\end{array}$ & 6 & 1 & 7 \\
\hline
\end{tabular}

Table (4): Percentage of different uterine pathologies detected by ultrasound in the study group.

\begin{tabular}{|c|c|c|c|c|c|}
\hline Fibroid & $\begin{array}{l}\text { Adeno- } \\
\text { myosis }\end{array}$ & $\begin{array}{l}\text { Endo- } \\
\text { metrial } \\
\text { polyp }\end{array}$ & $\begin{array}{l}\text { Congenital } \\
\text { anomalies }\end{array}$ & $\begin{array}{l}\text { Asherman } \\
\text { syndrome }\end{array}$ & Total \\
\hline No. 4 & 3 & 7 & 3 & 1 & 18 \\
\hline$\% \quad 13.33 \%$ & $10 \%$ & $23.33 \%$ & $10 \%$ & $3.3 \%$ & $60 \%$ \\
\hline
\end{tabular}

Table (5): Percentage of different tubal pathologies detected by ultrasound in the study group.

\begin{tabular}{lccl}
\hline Fallopian tube & Hydrosalpinx & Chocolate cyst & Total \\
\hline No & 1 & 3 & 4 \\
$\%$ & $3.3 \%$ & $10 \%$ & $13.3 \%$ \\
\hline
\end{tabular}

\section{Discussion}

Infertility constitutes a major social and psychological burden amongst couples and the prevalence is increasing. Conditions in the female partner account for the majority of cases of infertility [6]

Regarding distribution of primary and secondary infertility in our study; females complaining of primary infertility were 13 out of $30(43.3 \%)$, while females complaining of secondary infertility were 17 out of $30(56.7 \%)$.

Abrao et al., [7] stated that ovulatory dysfunction is more common in young age females (in their twenties).
This agreed with our study in which mean age of ovarian disorders was about 25.5 years old.

Ikpeme et al., [8] concluded that polycystic ovary (PCO) is the major finding in women with menstrual irregularity and infertility in the Calabar area, this agreed with our study in which females diagnosed as having PCO had irregular cycles.

Ajossa et al., [9] stated that both endometrial biopsy and TV US had similarly high specificity, but very low sensitivity for endometrial polyp diagnosis. The high sensitivity of TV US endometrial thickening may be essential in polyp detection.

Ahmadi et al., [10] concluded that three D hystero sonography (3-DHS) has a reliable specificity for diagnosis of uterine abnormalities and that sensitivity and specificity of three-dimensional hystero-sonography (3-DHS) and hysteroscopy in detecting polyp or hyperplasia, regarding histopathology as the gold standard was the same.

This partially agreed with Apirakviriya et al., [11] who stated that Three D-TV US demonstrated $84.1 \%$ diagnostic accuracy for detecting uterine cavity abnormalities in infertile women. A significant percentage of patients had evidence of uterine cavity pathology. Thus Hysteroscopy is recommended for accurate detection and diagnosis of uterine cavity lesion.

We agreed with Ajossa et al., [9] regarding the detection of endometrial polyp by TV US VS endometrial biopsy, they had nearly the same high specificity. Also the high sensitivity of TV US focal endometrial thickening is essential in polyp detection.

We also agreed with Ahmadi et al., [10] that (3DHS) has a reliable specificity in detecting uterine cavity abnormalities including polyp- and sub mucosal myoma but not hyperplasia when compared to histopathology as the gold standard.

Armar et al., [12] stated that results and experience strongly suggest that saline infusion sonohysterography (SIS) should be used as first line diagnostic modality in cases of sub-fertility being simple, yet extremely valuable technique for investigating benign uterine pathology and a reliable method of diagnosing tubal and uterine pathologies compared to X-ray hystero-salpingography (HSG) for cases of infertility.

This agreed with Darzi et al., [13] and Benkaddour et al., [14] who stated that (SIS) is a highly sensitive investigative modality and comparable to the gold standard tool, hysteroscopy, in the 
detection of intrauterine abnormalities in sub fertile women e.g. uterine polyps, sub-mucous myomas, uterine anomalies and intrauterine adhesions. It can be also used as a screening tool for sub fertile patients prior to IVF treatment.

Abdel-Gadir, [15] stated that 3D saline infusion sono-hysterography when available, could add useful information especially for mapping and documenting the extent of intrauterine pathology. However, both $2 \& 3$ D SIS techniques failed in diagnosing endometrial micropolyps which were seen only during hysteroscopy.

However there was a contradictory finding in a study performed by Sitimani et al., [16] who stated that the sensitivity of both TV US and SIS for detection of uterine cavity abnormalities in patients of infertility was low and they cannot be recommended as replacement for hysteroscopy.

We agreed with Darzi et al., [13] and Benkaddour et al., [14] that (SIS) is of great diagnostic value and could replace hysteroscopy in detecting endometrial polyp, sub mucous myomas and intrauterine adhesions where we discovered that out of seven cases suspected to have endometrial polyp, three of them underwent sono-hysterography that was highly assuring of the diagnosis of endometrial polyp, histopathology confirmed the diagnosis, while only one of the other seven cases was confirmed to be endometrial polyp depending on the sonographic picture and vascular pedicle sign only. The three other cases, histopathology revealed different diagnoses including disordered proliferative endometrium and endometrial hyperplasia.

Also two other cases underwent sonohysterography being suspected to be submucus myoma and intrauterine adhesion, diagnosis was confirmed following surgical removal and hysteroscopy respectively.

Dreisler and Sorensen, [17] concluded that Mullerian duct anomalies were more frequent in nulliparous women except sub septate uterus that frequently presented by recurrent miscarriage.

We agreed with Dreisler and Sorensen [17], regarding the presentation of hypoplastic uteus in nulliparus women while disagreed with them regarding bicornuate uterus and sub septate uterus who presented by repeated miscarriage in our study.

Athanasiadis et al., [18] stated that 3D US appears to be a very accurate method for the diagnosis of congenital uterine anomalies. This agreed with Moini et al., [19] who further added that increased experience will improve accuracy in the diagnosis of arcuate uterus and septate uterus with short septum. This also agreed with both Graupera et al., [20] and Bermejo et al., [21] who concluded that 3D-US has proven to be just as effective as MRI in the diagnosis of uterine malformations. It is also more economical and better tolerated by patients and this should decrease the need for invasive techniques such as laparoscopy and hysteroscopy, which could potentially be reserved for those women requiring therapeutic intervention.

We agreed with Moini et al., [19], Athanasiadis et al., [18] Graupera et al., [20] and Bermejo et al., [21], that 3D sonography has a high level of accuracy regarding diagnosis of uterine anomalies and is comparable to MRI regarding this point where we had two cases of uterine anomalies suggested by presence of two diveregent endometrial echogenic stripes, where three D ultrasound revealed the diagnosis of bicornuate uterus and sub-septate uterus. Diagnosis was confirmed by MRI.

Sokalska et al., [22] concluded that by using subjective evaluation of gray-scale and Doppler ultrasound findings, it is possible to make an almost conclusive diagnosis of endometrioma and hydrosalpinx.

We agreed with Sokalska et al., [22] about the diagnosis of hydrosalpinx and endometrioma by using subjective evaluation of gray-scale and colour Doppler ultrasound findings as we had a case of hydrosalpinx suggested by finding serpigenous tubular strcture with in complete septations. Diagnosis of hydrosalpinx was confirmed using X-ray HSG as gold standard investigation.

Also three out of three cases were highly suggested to be endometrioma by transvaginal ultrasound (complex cyst with low level internal echos, no color flow inside on color Duplex examination, one of them had echogenic a vascular solid component adherent to the wall representing retracted thrombus); diagnosis was confirmed by histopathology following surgical removal.

Bosch and Schoubroeck, [23] stated that Both a high quality ultrasound machine and a high level of expertise will optimize diagnostic accuracy of real-time dynamic transvaginal ultrasonography as the first test in the diagnosis of both endometriosis and adenomyosis.

Our study dedicated that ultrasound interpretation of grey scale and color Doppler revealed high diagnostic capability in diagnosis of endometrioma compared to histopathology following excision of 
these lesions, however because our study is limited, so we could not confirm the true extent of lesions throughout the pelvis. Further correlation with MRI is recommended.

Cunningham et al., [24] stated that the widespread use of trans vaginal ultrasound has allowed for a better understanding of the scope of adenomyosis, particularly if multiple US findings manifest and is now the primary imaging modality for diagnosis. However diagnosis might require extensive ultrasound skills as stated by Bosch et al., [23] and Dueholm et al., [25] who stated that standardized pattern recognition during real-time $2 \mathrm{D}$ TV US may result in good agreement between expert and non expert raters for the diagnosis of adenomyosis.

However there was a contradictory finding by Arban et al., [26] who stated that MRI should be included in the diagnostic pathway of adenomyosis in infertile women because TV US has a limited diagnostic accuracy in the detection of overall adenomyosis, especially in case of associated findings.

Our study agreed with Cunningham et al., [24] about the high diagnostic accuracy of transvaginal ultrasound in diagnosis of adenomyosis (using MRI as gold standard investigation) especially when multiple findings co exist, as we had two cases of diffuse adenomyosis and another case of focal adenomyoma that was highly suggested by transvaginal ultrasound, MRI confirmed the diagnosis. The lesion had indistinct endometrialmyometrial junction, sub endometrial cysts and blood flow through the lesion (that is relatively increased in comparison to the other uterine wall) in contrast the peri-lesional blood flow in case of fibroid.

Jones et al., [27] stated that while the imaging appearance of a cervical mass can be diagnostic, histopathologic examination is still necessary in some cases, particularly when malignancy is suspected.

We agreed with Jones et al., [27] that any cervical mass should be further evaluated following surgical removal because malignancy of the cervix is by far the most serious finding, hence the case of cervical mass in our study underwent surgical intervention and was proved pathologically to be cervical fibroid.

Despite the fact that this study has limitations due to small number of patients, we believe it could become a base line and give guidance for other future studies.

\section{Conclusion:}

Ultrasound has become a reliable tool in the diagnosis of many anatomical causes of female infertility and is comparable to gold standard investigations in many circumstances, so we recommend it as primary investigation modality that could be complemented by other tools e.g. MRI, HSG, and laparoscopy when needed.

\section{References}

1- VANDER B.M. and WYNS C.: Fertility and infertility: Definition and epidemiology: Clinical Biochemistry journal, Volume 62, Pages 2-10, 2018.

2- DISHUCK C.F., GUNN D.D., et al.: Advanced Imaging in Female Infertility; Curr. Urol. Rep., Nov. 16; 20 (11): 77. doi: 10.1007/s11934-019-0942-0, 2019.

3- SADOW C.A. and SAHNI V.A.: Imaging female infertility Abdominal Imaging, 1; 39 (1): 92-107, 2014.

4- PANCHAL $S$. and VIJAYARAGHAVAN B.: Ultrasound: Principles and Applications IN: Jayaprakasan K., Panchal S. and Homburg R. (eds): Ultrasound in Sub-fertility Routine Applications and Diagnostic Challenges.: Jaypee Brothers Medical Publishers (P) LTD, First Edition, p. 15-26, 2014.

5- ABUHAMAD A.Z., BENACERRAF B.R., et al.: Consider ultrasound first for imaging the female pelvis, American Journal of Obstetrics \& Gynecology, Volume 212, Issue 4: p. 450-455, 2015.

6- OLOOTO, WASIU, ENIOLA, et al.: A review of Female Infertility; important etiological factors and management. Journal of Microbiology and Biotechnology Research, Vol. 2: p. 379-385, 2012.

7- ABRAO M.S., MUZII L. and MARANA R.: Anatomical causes of female infertility and their management. International Journal of Gynecology and Obstetrics, 123: S 18S24, 2013.

8- IKPEME A.A., UDO A.E. and ANI N.E.: Transvaginal ultrasound assessment of womenpresenting with infertility and menstrual irregularity in Calabar, Nigeria: Niger Postgrad Med. J., 21 (3): 262-365, 2014.

9- AJOSSA S., CAPPAI A., CORDA V., et al.: Tubal Diseases In: Alcazar J.L. Guerriero S. and Martins W.P. eds.: Managing ultrasonography in human reproduction. Springer International Publishing Switzerland, p. 29-42, 2017.

10-AHMADI F., RASHIDY Z., HAGHIGHI H., et al.: Uterine cavity assessment in infertile women: Sensitivity and specificity of three-dimensional Hysterosonography versus Hysteroscopy. Iranian Journal of Reproductive Medicine, 11 (12): 977-982, 2013.

11- APIRAKVIRIYA C., RUNGRUXSIRIVORN T., et al.: Diagnostic accuracy of 3D-transvaginal ultrasound in detecting uterine cavity abnormalities in infertile patients as compared with hysteroscopy. Eur. J. Obstet. Gynecol. Reprod Biol., 200: 24-28, 2016.

12- ARMAR A., IZHAR F.A., MANSURI N.A., et al.: Diagnostic accuracy of Saline Infusion sonohysterosalpingography (SIS) as compared to Hysterosalpingography: Journal Of Pakistan Medical Association, June Vol. 69: p. 223-254, 2019. 
13- DARZI S.N., GHORBANI R. and MORADAN S.: Diag nostic value of saline infusion sonohysterography for detecting endometrial focal lesion. Pan. Afr. Med. J., 33: $211,2019$.

14- BENKADDOUR A., YGERVAISE A. and FERNANDEZ H.: Which is the method of choice for evaluating uterine cavity in infertility workup? J. Gynecol. Obstet. Biol. Reprod (Paris), 39 (8): 606-613, 2010.

15- ABDEL-GADIR A.: The Measurable and Unmeasurable Visual Benefits of 3D Saline Infusion Sonohysterography. Journal of Clinical Case Report, Vol. 9: p. 1220. doi 10.4172/2165-7920.10001220, 2019.

16- SITIMANI ANITA, CHAWL A. INDU, VOHRA, et al.: Saline infusion sonography in evaluation of uterine cavity abnormalities in infertility: A comparative study. International Journal of Reproduction, Contraception, Obstetrics and Gynecology, [S.1.], V. 5, N. 9, p. 2995-3000. ISSN 2320-1789, 2017.

17- DREISLER E. and SØRENSEN S.: Müllerian duct anomalies diagnosed by saline contrast sono-hysterography: Prevalence in a general population: Fertility and Sterility Journal, Volume 102, Issue 2, Pages 525-529, 2014.

18- ATHANASIADIS A.P., GRIMBIZIS G.F., KARAVIDA A., et al.: Three-dimensional ultrasound in the diagnosis and the classification of congenital uterine anomalies using the ESHRE/ESGE classification: A diagnostic accuracy study: Archives of Gynecology and Obstetrics Journal, Vol. 299, pages 779-789, 2019.

19- MOINI A1, MOHAMMADI S., HOSSEINI R., et al.: Accuracy of 3-dimensional sonography for diagnosis and classification of congenital uterine anomalies; J. Ultrasound Med., Jun., 32 (6): 923-7. doi: 10.7863/ultra.32.6. 923, 2013

20- GRAUPERA B, PASCUAL M.A., HERETER L., et al.: Accuracy of three-dimensional ultrasound compared with magnetic resonance imaging in diagnosis of Müllerian duct anomalies using ESHRE-ESGE consensus on the classification of congenital anomalies of the female genital tract. Ultrasound Obstet. Gynecol., Vol. 46: p. 616-622, 2015.

21- BERMEJO C., MARTÍNEZ TEN P., CANTARERO R., et al.: Three-dimensional ultrasound in the diagnosis of Müllerian duct anomalies and concordance with magnetic resonance imaging. Ultrasound Obstet. Gynecol. J., 35 (5): 593-601, 2010

22- SOKALSKA A., TIMMERMAN D., et al.: Diagnostic accuracy of transvaginal ultrasound examination for assigning a specific diagnosis to adnexal masses. Ultrasound Obstet. Gynecol J., 34: 462-470. doi:10.1002/ uog.6444, 2009.

23- BOSCH V.T., de BRUIJN A.M., de LEEUW R.A., et al.: Sonographic classification and reporting system for diagnosing adenomyosis. Ultrasound Obstet. Gynecol., 53 (5): 576-582, 2019.

24- CUNNINGHAM R.K., HORROW M.M., SMITH R.J. and SPRINGER J.: Adenomyosis: A Sonographic Diagnosis. Radiographics, 38 (5): 1576-1589, 2018.

25- DUEHOLM M., RASMUSSEN C.K. and HANSEN E.S.: Inter-rater agreement in the diagnosis of adenomyosis by 2- and 3-dimensional transvaginal ultrasonography. $\mathbf{J}$. Ultrasound Med., 38 (3): 657-666, 2019.

26- ARBAN F., BOTTARO L., COVA M.A., et al.: Diagnostic accuracy of TV US osis in diagnosis of adenomyosis in infertile women, ECR, / C-2539, 2019.

27- JONES L.P., LANGER J.E., WILDENBERG J.C., et al.: US of the Non gravid Cervix with Multimodality Imaging Correlation: Normal Appearance, Pathologic Conditions and Diagnostic Pitfalls. RSNA Radiographics Journal, 2 (36): 765-89, 2016. 


\section{دور التصوير بالموجات الفوق صوتية (السونار)

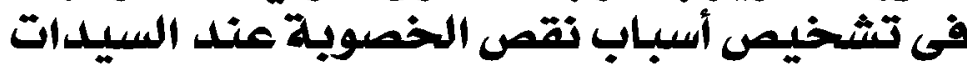

$$
\text { الخلفية: إن دراسة الأسباب المحتملة للعقم عند للسيدات عملية ليست بسيطة وتحتاج كثير من الأدوات التشخيصية. }
$$

هدف العمل: مناقثة دور الموجات فوق الصوتية في الكثف عن أسباب العقم عند العيدات (بما في ذلك أمراض الرحم والمبيضين وعنق الرحم وقناة فالوب) موضحة بيعض منئة الحالات.

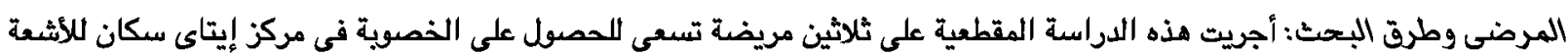

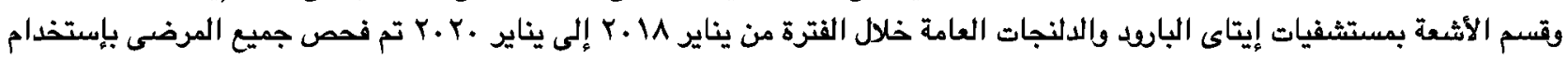
جهاز الموجات فوق الصوتية (Machines MedisonSono Ace R3 Ultrasound و Toshiba Nemio 30 GE Healthcare Voluson P8).

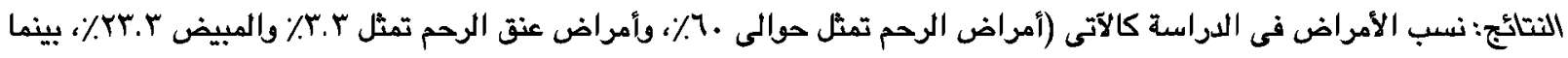

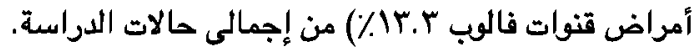

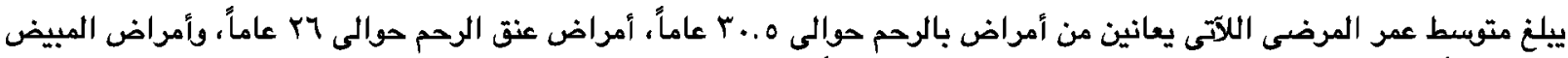

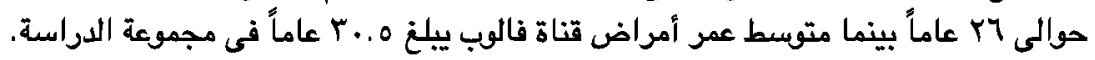

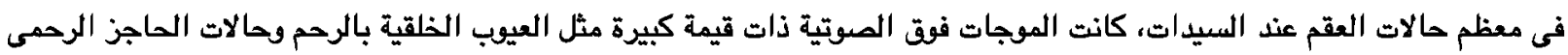

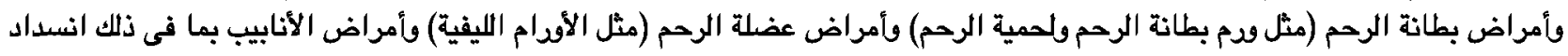
قناتى فالوب وبطانة الرحم المهاجرة، والأمراض الوظيفية للمبيضين مثل تكيسات المبيضين وأمراض عنق الرحم (مثل أودام عنق الرحم). الخلاصة:كانت الموجات فوق الصوتية أداة موثوقة فى تشخيص العديد من الأسباب التشريحية لعقم الإناث ويمكن مقارنتها مع الدراسات

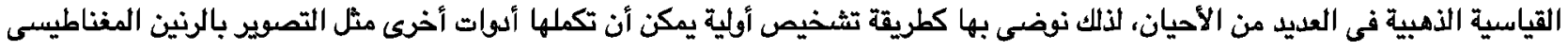

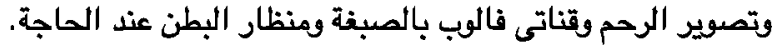

